\title{
Normal Vaginal Delivery in a Woman with COVID-19
}

\author{
Behjat Khorsandi ${ }^{1}$, Nasrin Nasirzadeh ${ }^{1} \stackrel{\mathrm{iD}}{ }$, Leila Asadi ${ }^{2} *$
}

1. Afshar Hospital, Shahid Sadoughi University of Medical Sciences, Yazd, Yazd, Iran

2. Department of Midwifery and Reproductive Health, Faculty of Nursing and Midwifery,

Tehran University of Medical Sciences, Tehran, Iran

*Correspondence: Leila Asadi, Department of Midwifery and Reproductive Health, Faculty of Nursing and Midwifery, Tehran University of Medical Sciences, Tehran, Iran.

Te: +989356518775

Email: asadi.midwife@gmail.com

Received December 10, 2020

Accepted December 30, 2020

\begin{abstract}
Background: The results of studies on the outcomes and course of coronavirus disease-2019 (COVID-19) in pregnant women are inconsistent. Proper characterization of the disease process can help healthcare providers in the accurate management and control of the disease in vulnerable individuals, particularly pregnant women. We herein report a case of a multiparous pregnant woman with COVID-19.

Case description: A 30-year-old pregnant woman (gravida 3 para 2) with gestational age of 39 weeks and six days and a history of occasional fever and chills in the past week was admitted to the midwifery triage with complaints of myalgia as well as severe pubic symphysis and back pain. The patient had the following vital signs at admission: fetal heart rate: 140 beats/min, oxygen saturation: $96 \%$, temperature: $37 \mathrm{oC}$, respiratory rate: 17 breaths/min, pulse rate: 126 beats/min and blood pressure: 100/70 $\mathrm{mmHg}$. The mother was positive for COVID-19 in both PCR and chest CT-scan findings, which demonstrated presence of multiple opacities in both lungs in favor of viral pneumonia.

Vaginal delivery was performed and an apparently healthy, term and cephalic baby girl was born with an Apgar score of 9 at one minute and 10 at five minutes after birth. The baby was negative for COVID-19 based on the molecular testing.

Conclusion: With proper management and timely separation of the mother from the baby and preparing breast milk by a non-infected person, no maternal or neonatal complications were observed in our case. More studies are required to gain a better understating about the possible morbidities and mortalities associated with COVID-19 during pregnancy.
\end{abstract}

Keywords: Pregnancy; COVID-19; Vaginal delivery 


\section{INTRODUCTION}

The coronavirus disease-2019 (COVID-19) outbreak spread rapidly in China and beyond. Evidence suggests that the disease can be spread from person to person through respiratory droplets expelled from the mouth and nose. However, the possibility of fecaloral transmission has been raised $(1,2)$.

According to the World Health Organization (WHO), there were 25,842,652 confirmed COVID-19 cases and 858,629 deaths from December 2019 until now (September 3, 2020). The number of confirmed cases in Iran has been reported to be 378,752 , while 21,797 COVID-related deaths have been reported (3).

With the continuous rise in the number of confirmed cases and the mortality rates worldwide, identification of vulnerable individuals is of great importance (4). Pregnant women are among those who are vulnerable to COVID-19 infection. Research shows that the coronavirus infection has been associated with maternal and fetal complications (5-8). To date, none of the studies confirmed placental transmission of the infection during pregnancy (9-11). Low weight, preterm delivery, fetal respiratory distress and neonatal death have been reported as some complication of COVID19 in pregnant women $(12,13)$.

Due to the physiological changes in the immune and cardiopulmonary systems during pregnancy, pregnant women may develop a more severe illness after viral respiratory infections. Based on evidence, most women suspected of having COVID19 have undergone cesarean section, but newborns of women who had normal delivery were also negative for COVID-19. There has been no report of vertical motherto-fetus transmission of COVID-19 (14-17). In a study by Dashraath et al. on 55 pregnant women with COVID-19 and 49 infants, there was no evidence of mother-to-fetal vertical transmission, and cesarean section was performed to terminate the pregnancy because of emergencies (6). However, in a study by Buonsenso et al., two COVID-19positive infants were identified after a twoweek follow up (despite the fact that the infants were asymptomatic) (3). There was also a case of 15-day-old infant with COVID-19. The infant was born by cesarean section to a mother with fever and lethargy (18). Proper identification of the disease in pregnant women can help healthcare providers in the management and accurate control of the disease in this sensitive group. Since COVID-19 is an emerging disease and there is still a lot to learn about the infection process, we aimed to report of a case of a pregnant woman with COVID-19 who had normal delivery.

\section{CASE PRESENTATION}

A 30-year-old pregnant woman (gravida 3 para 2) with gestational age of 39 weeks and six days and a history of occasional fever and chills in the past week was admitted to the midwifery triage with complaints of myalgia as well as severe pubic symphysis and back pain. Fetal cardiotocograph was normal. Vaginal examination showed that her cervix was $4 \mathrm{~cm}$ dilated, $30 \%$ effaced and -3 station. The fetus had cephalic presentation. Vital signs at admission were as follows: fetal heart rate: 140 beats/min, oxygen saturation (SPO2): 96\%, temperature: $37 \mathrm{oC}$, respiratory rate (RR): 17 breaths/min, pulse rate (PR): 126 beats/min, blood pressure (BP): 100/70 mmHG. Since the mother had a history of fever and chills, complete blood count, blood grouping and $\mathrm{Rh}$ typing, C-reactive protein (CRP), erythrocyte sedimentation rate (ESR), urine analysis tests were requested (Table 1$)$. 
Table 1. Laboratory findings at time of admission and after delivery

\begin{tabular}{|c|c|c|c|c|c|c|}
\hline Variable & $\begin{array}{c}\text { White blood cell } \\
\text { count }\end{array}$ & $\begin{array}{c}\text { Platelet } \\
\text { count }\end{array}$ & Lymphocyte & ESR & CRP & Urine analysis \\
\hline $\begin{array}{c}\text { At } \\
\text { Time }\end{array}$ & 12,300 & 385,000 & $\begin{array}{c}21.30 \\
(2619.9)\end{array}$ & 57 & + & $\begin{array}{c}\text { RBC= Many } \\
\text { Keton+ } \\
\text { Other: Normal }\end{array}$ \\
\hline $\begin{array}{c}\text { An hour } \\
\text { after } \\
\text { delivery }\end{array}$ & 17,600 & 331,000 & $\begin{array}{c}11.50 \\
(2024)\end{array}$ & 81 & +++ & \\
\hline
\end{tabular}

Thirty minutes after hospitalization, vaginal and anatomical examinations were carried out, which indicated $6 \mathrm{~cm}$ dilation, $80 \%$ effacement, 0 station, artificially opened amniotic sac and thick meconium. Immediately after amniotomy, monitoring was performed and simple Ringer's solution was infused. Twenty minutes later, vaginal delivery was performed and an apparently healthy, term and cephalic baby girl was born with an Apgar score of 9 at one minute and 10 at five minutes after birth. The baby had $2.7 \mathrm{~kg}$ weight, $48 \mathrm{~cm}$ height a head circumference of $32.5 \mathrm{~cm}$. Based on the ESR and CRP findings, the mother was transferred to the isolation room. The infectious diseases specialist recommended high-resolution CT-scan and polymerase chain reaction (PCR) test due to COVID-19 suspicion. At day two of admission, CT-scan findings demonstrated presence of multiple opacities in both lungs in favor of viral pneumonia (Figure 1). Therefore, the mother received hydroxychloroquine $(400 \mathrm{mg}$ ) bds, diphenhydramine syrup $\mathrm{q} 8 \mathrm{~h}$, ceftriaxone injection $\mathrm{q} 6 \mathrm{~h}$ and vitamin $\mathrm{C}$ supplement q1d. Due to the lung involvement in CTscan, the baby was separated from the mother and fed through breast milk according to pediatrician recommendations. On the third day, PCR was performed for both the mother and the newborn.

Figure 1. Chest CT-scan of the mother

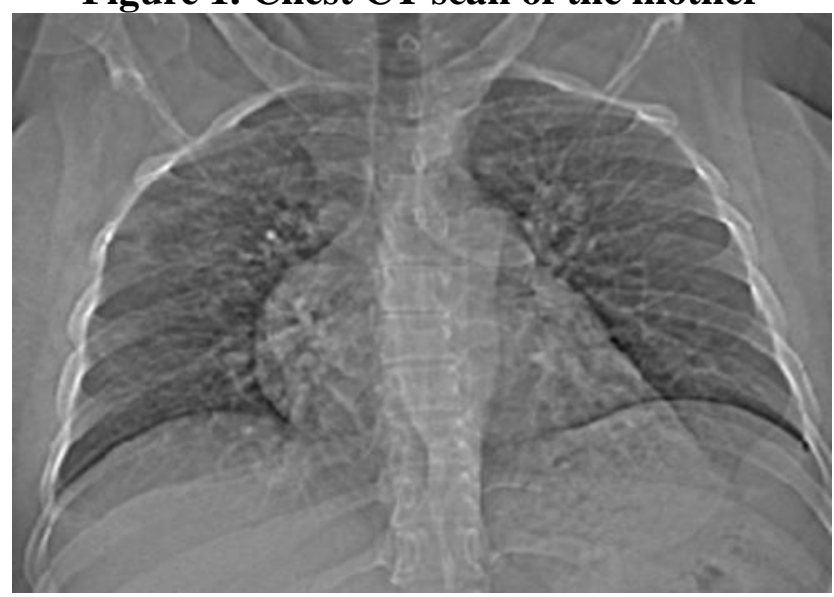


The patient was discharged from the hospital and was recommended to selfisolate at home for two weeks. The patient was advised to contact an infectious disease specialist in case of shortness of breath and cough and to check the results of the requested laboratory tests three days after the discharge. At time of discharge, the mother had BP of $100 / 65 \mathrm{mmHg}$, PR of 82 , RR of 17 breaths/min, temperature of $37 \mathrm{oC}$ and SPO2 of $96 \%$. The patient was also advised to take hydroxychloroquine tablets (400 mg) bds, fresolin tablets (60mg) q1d and amoxicillin $(500 \mathrm{mg}$ ) q8h. Based on the PCR test, both the mother and the baby were negative for COVID-19. The baby had no sign of respiratory infection or pneumonia.

\section{DISCUSSION}

We herein reported a 30-year-old multiparous pregnant woman with COVID19 who had natural delivery at gestational age of 40 weeks and three days. In a study on three pregnant women with COVID-19, two subjects were multiparous and aged 3034 years with no history of underlying disease. One mother had normal delivery, while the remaining two underwent cesarean section. The newborns had no symptoms of respiratory distress (19). In a study by Chen et al. on nine pregnant women with COVID19 who were admitted to a hospital in Wuhan, China, five were full term and all subjects underwent cesarean section(20). In other studies, normally delivered infants had no sign of infection $(2,14,21,22)$. In a study on 116 pregnant women with COVID$19,85.9 \%$ of subjects underwent cesarean section, of which $33 \%$ were terminated due to the disease, symptoms of pneumonia and other indications including multiple repeat caesarean sections, preeclampsia, placenta previa and fetal growth retardation. The mentioned study also found no significant association between route of delivery and risk of fetal infection (22).

At time of admission, our case had fever, chills and myalgia. Ambrosino et al. reported fever (54\%), cough $(35 \%)$ and myalgia $(17 \%)$ as the most common symptoms of COVID-19 in pregnant women(23). Irani et al. also reported fever (89.1\%), cough $(72.2 \%)$ and fatigue $(42.5 \%)$ as the most common symptom in pregnant(24). The most common symptoms of COVID-19 have been reported to be fever, shortness of breath and dry cough. However, some patients may experience other symptoms such as dizziness, nasal congestion, rhinorrhea, sore throat, abdominal pain, nausea or diarrhea $(25,26)$. According to previous reports, COVID-19 causes multiple maternal and neonatal complications including abortion, preterm delivery, premature rupture of membranes, respiratory distress, low birth weight, hospitalization in neonatal intensive care unit and stillbirth(10, 23, 27, 28). In our case, the infant had no complication and was born with Apgar score of 9 at one minute. Similarly, some studies reported no severe neonatal and maternal complication (15).

Since our case was COVID-19- positive and symptomatic, she was separated from the baby and the baby was fed with breast milk. After the discharge, no sign of pneumonia was observed in the baby. Augusto et al. confirmed the safety of breastfeeding in mothers with COVID-19 (29). In a study by Wu et al., of three breast milk samples, one sample was positive for COVID-19 in PCR on the first day after delivery but negative in the follow-up on the third day. The other two samples were negative (30). Due to the presence of antiviral antibodies in breast milk, breastfeeding could have potential protective effect on the baby (31).

\section{CONCLUSION}

With proper management of pregnant woman and timely separation of the mother from the baby and preparing breast milk by a non-infected person, no maternal or neonatal complications were observed in our case. Raising public awareness about the 
disease, especially in high-risk individuals, such as pregnant women is of upmost importance. More studies are required to gain a better understating about the possible morbidities and mortalities associated with COVID-19 during pregnancy.

\section{DECLARATIONS \\ Funding}

Not applicable.

\section{Ethics approvals and consent to participate}

Written informed consent was obtained from patient prior to participation in the study.

\section{Conflict of interest}

The author declares that there is no conflict of interest regarding publication of this article.

\section{REFERENCES}

1. Li J-Y, You Z, Wang Q, Zhou Z-J, Qiu Y, Luo R, et al. The epidemic of 2019-novelcoronavirus (2019-nCoV) pneumonia and insights for emerging infectious diseases in the future. Microbes and infection. 2020;22(2):80-5.

https://doi.org/10.1016/j.micinf.2020.02.002

2. Gagneur A, Dirson E, Audebert S, Vallet S, Legrand-Quillien $M$, Laurent $\mathrm{Y}$, et al. Materno-fetal transmission of human coronaviruses: a prospective pilot study. European Journal of Clinical Microbiology \& Infectious Diseases. 2008;27(9):863-6. https://doi.org/10.1007/s10096-008-0505-7

\section{Buonsenso D, Costa S, Sanguinetti M,} Cattani P, Posteraro B, Marchetti S, et al. Neonatal late onset infection with severe acute respiratory syndrome coronavirus 2 . American journal of perinatology. 2020;37(8):869.

https://doi.org/10.1055/s-0040-1710541

4. Ayenigbara IO. COVID-19: An
International Public Health Concern. Central Asian Journal of Global Health. 2020;9(1).

https://doi.org/10.5195/cajgh.2020.466

5. Payne DC, Iblan I, Alqasrawi S, Al Nsour M, Rha B, Tohme RA, et al. Stillbirth during infection with Middle East respiratory syndrome coronavirus. The Journal of infectious diseases. 2014;209(12):1870-2. https://doi.org/10.1093/infdis/jiu068

6. Dashraath P, Jeslyn WJL, Karen LMX, Min LL, Sarah L, Biswas A, et al. Coronavirus disease 2019 (COVID-19) pandemic and pregnancy. American journal of obstetrics and gynecology. 2020. https://doi.org/10.1016/j.ajog.2020.03.021

7. Robertson CA, Lowther SA, Birch T, Tan C, Sorhage F, Stockman L, et al. SARS and pregnancy: a case report. Emerging infectious diseases. 2004;10(2):345. https://doi.org/10.3201/eid1002.030736

8. Assiri A, Abedi GR, Al Masri M, Bin Saeed A, Gerber SI, Watson JT. Middle East respiratory syndrome coronavirus infection during pregnancy: a report of 5 cases from Saudi Arabia. Clinical Infectious Diseases. 2016;63(7):951-3.

https://doi.org/10.1093/cid/ciw412

9. Poon LC, Yang H, Dumont S, Lee J, Copel J, Danneels L, et al. ISUOG Interim Guidance on coronavirus disease 2019 (COVID - 19) during pregnancy and puerperium: information for healthcare professionals-an update. Ultrasound in Obstetrics \& Gynecology. 2020;55(6):848. https://doi.org/10.1002/uog.22061

10. Panahi L, Amiri M, Pouy S. Risks of novel coronavirus disease (COVID-19) in pregnancy; a narrative review. Archives of academic emergency medicine. 2020;8(1).

11. Banaei M, Ghasemi V, Saei Ghare Naz 
M, Kiani Z, Rashidi-Fakari F, Banaei S, et al. Obstetrics and neonatal outcomes in pregnant women with covid-19: A

systematic review. Iranian Journal of Public Health. 2020;49:38-47.

https://doi.org/10.18502/ijph.v49iS1.3668

12. Muhidin S, Moghadam ZB, Vizheh M. Analysis of Maternal Coronavirus Infections and Neonates Born to Mothers with 2019nCoV; a Systematic Review. Archives of Academic Emergency Medicine. 2020;8(1). https://doi.org/10.1080/14767058.2020.1832 073

13. Zhu $\mathrm{H}$, Wang $\mathrm{L}$, Fang $\mathrm{C}$, Peng $\mathrm{S}$, Zhang L, Chang G, et al. Clinical analysis of 10 neonates born to mothers with 2019nCoV pneumonia. Translational pediatrics. 2020;9(1):51.

https://doi.org/10.21037/tp.2020.02.06

14. Rasmussen SA, Smulian JC, Lednicky JA, Wen TS, Jamieson DJ. Coronavirus Disease 2019 (COVID-19) and Pregnancy: What obstetricians need to know. American journal of obstetrics and gynecology. 2020. https://doi.org/10.1097/AOG.000000000000 4290

15. Li N, Han L, Peng M, Lv Y, Ouyang Y, Liu $\mathrm{K}$, et al. Maternal and neonatal outcomes of pregnant women with COVID19 pneumonia: a case-control study. Clinical infectious diseases. 2020.

https://doi.org/10.1101/2020.03.10.2003360 5

16. Mullins E, Evans D, Viner R, O'Brien $\mathrm{P}$, Morris E. Coronavirus in pregnancy and delivery: rapid review. Ultrasound in Obstetrics \& Gynecology. 2020;55(5):58692.

https://doi.org/10.1002/uog.22014

17. Chen S, Huang B, Luo D, Li X, Yang F, Zhao Y, et al. Pregnant women with new coronavirus infection: a clinical characteristics and placental pathological analysis of three cases. Zhonghua bing li xue za zhi $=$ Chinese journal of pathology. 2020;49:E005-E.

18. Kamali Aghdam M, Jafari N, Eftekhari $\mathrm{K}$. Novel coronavirus in a 15-day-old neonate with clinical signs of sepsis, a case report. Infectious Diseases. 2020;52(6):4279.

https://doi.org/10.1080/23744235.2020.1747 634

19. Liu W, Wang Q, Zhang Q, Chen L, Chen J, Zhang B, et al. Coronavirus disease 2019 (COVID-19) during pregnancy: a case series. 2020.

20. Chen H, Guo J, Wang C, Luo F, Yu X, Zhang W, et al. Clinical characteristics and intrauterine vertical transmission potential of COVID-19 infection in nine pregnant women: a retrospective review of medical records. The Lancet. 2020;395(10226):80915.

https://doi.org/10.1016/S0140-

6736(20)30360-3

21. Mullins E, Evans D, Viner R, O'Brien $\mathrm{P}$, Morris E. Coronavirus in pregnancy and delivery: rapid review and expert consensus. medRxiv. 2020.

https://doi.org/10.1101/2020.03.06.2003214 4

22. Yan J, Guo J, Fan C, Juan J, Yu X, Li J, et al. Coronavirus disease 2019 (COVID-19) in pregnant women: A report based on 116 cases. American journal of obstetrics and gynecology. 2020.

https://doi.org/10.1016/j.ajog.2020.04.014

23. Gajbhiye R, Modi D, Mahale S. Pregnancy outcomes, Newborn complications and Maternal-Fetal Transmission of SARS-CoV-2 in women with COVID-19: A systematic review. medRxiv. 2020.

https://doi.org/10.1101/2020.04.11.2006235 6 
24. Irani M, Pakfetrat A, Mask MK. Novel coronavirus disease 2019 and perinatal outcomes. Journal of Education and Health Promotion. 2020;9.

https://doi.org/10.4103/jehp.jehp_189_20

25. Jin X, Lian J-S, Hu J-H, Gao J, Zheng L, Zhang Y-M, et al. Epidemiological, clinical and virological characteristics of 74 cases of coronavirus-infected disease 2019 (COVID-19) with gastrointestinal symptoms. Gut. 2020;69(6):1002-9.

https://doi.org/10.1136/gutjnl-2020-320926

26. Huang C, Wang Y, Li X, Ren L, Zhao J, $\mathrm{Hu} \mathrm{Y}$, et al. Clinical features of patients infected with 2019 novel coronavirus in Wuhan, China. The lancet. 2020;395(10223):497-506. https://doi.org/10.1016/S01406736(20)30183-5

27. Ambrosino P, Storino A, Lupoli R, Calcaterra I, Papa A, Spedicato GA, et al. Pregnancy and Perinatal Outcomes in Women with SARS-CoV-2 Infection: A Meta-Analysis with Meta-Regressions. Available at SSRN 3582754. 2020. https://doi.org/10.2139/ssrn.3582754
28. de Oliveira FLB, da Cunha Germano BC, Junior GBC, de Moura AMMA, de Sena Pereira N. Coronavirus in Pregnant Women: Literature Review. American Scientific Research Journal for Engineering, Technology, and Sciences (ASRJETS). 2020;67(1):73-9.

29. Pereira A, Cruz-Melguizo S, Adrien M, Fuentes L, Marin E, Forti A, et al. Breastfeeding mothers with COVID-19 infection: a case series. International breastfeeding journal. 2020;15(1):1-8. https://doi.org/10.1186/s13006-020-00314-8

30. Wu Y, Liu C, Dong L, Zhang C, Chen Y, Liu J, et al. Coronavirus disease 2019 among pregnant Chinese women: case series data on the safety of vaginal birth and breastfeeding. Bjog. 2020;127(9):1109. https://doi.org/10.1111/1471-0528.16276

31. Fernández-Carrasco FJ, Vázquez-Lara JM, González-Mey U, Gómez-Salgado J, Parrón-Carreño T, Rodríguez-Díaz L. Coronavirus Covid-19 infection and breastfeeding: an exploratory review. Revista espanola de salud publica. 2020;94.

How to Cite: Khorsandi B, Nasirzadeh N, Asadi L. Normal Vaginal Delivery in a Woman with COVID-19. jcbr. 2020; 4 (4) :34-40 